\title{
Smoking, alcohol consumption, and illicit substances use among adolescents in Poland
}

\author{
Maria Nowak, Malgorzata Papiernik, Alicja Mikulska and Bozena Czarkowska-Paczek* (D)
}

\begin{abstract}
Background: The use of alcohol, tobacco, and illicit substances typically first occurs in adolescence. The purpose of this study was to examine alcohol, cigarette, and illicit substance use among adolescents in Poland, including the age of initiation, frequency of use, methods of access, location of use, and parental knowledge and attitude.

Methods: An author-derived questionnaire was used to cross-sectionally survey 541 participants aged 13-17 years old. Due to the fact that some answers were lacking, the number of questionnaires analysed was 538 in case of smoking and illicit substances use, and 535 in case of alcohol drinking.

Results: The use of alcohol, cigarette, and illicit substance among the investigated group was 36.1, 37.6, and $10.8 \%$ respectively. The average age of initiation was 13-14 years old. Parents were aware of alcohol, cigarette, and illicit substance use $49.5,35.8$ and $22.4 \%$ of the time, respectively, and the rate of acceptance was 5.7 and $6.7 \%$ for alcohol and cigarettes. More than 28\% of participants smoked in school, and $32.7 \%$ accessed illicit substances in the school's neighborhood.

Conclusions: The rate of alcohol, cigarette, and illicit substance use in Poland is high and increasing, despite globally designed preventative actions. Parents' awareness of children's alcohol, cigarette, or illicit substance use is low, and schools hardly fulfil their educational and protective role. Preventative actions are necessary, and local challenges should be considered.
\end{abstract}

Keywords: Alcohol use, Cigarette use, Illicit substance use, Parental acceptance of abuse, Adolescents

\section{Background}

The use of alcohol, tobacco, and illicit substances typically first occurs in adolescence. Adolescents usually start with cigarettes and alcohol, and these substances often precede the subsequent use of illicit substances. In addition, the close relationship between cigarettes smoking and the use of alcohol and drugs has been established in the literature [1-3]. It has been reported that people who start smoking and alcohol drinking in adolescence have an increased probability of having substance use problems in adulthood $[4,5]$. Drinking itself, especially initiated in childhood, is associated with a wide range of negative outcomes including suicide ideation, violence, injury, depression, and school

\footnotetext{
*Correspondence: dom_paczek@o2.pl; bozena.czarkowskapaczek@wum.edu.pl

Department of Clinical Nursing, Medical University of Warsaw, E. Ciolka Street 27, 01-445 Warsaw, Poland
}

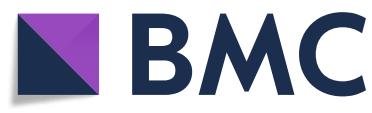

(c) The Author(s). 2018 Open Access This article is distributed under the terms of the Creative Commons Attribution 4.0 International License (http://creativecommons.org/licenses/by/4.0/), which permits unrestricted use, distribution, and

reproduction in any medium, provided you give appropriate credit to the original author(s) and the source, provide a link to the Creative Commons license, and indicate if changes were made. The Creative Commons Public Domain Dedication waiver (http://creativecommons.org/publicdomain/zero/1.0/) applies to the data made available in this article, unless otherwise stated. 
women [12]. Because smoking and illicit substances-related problems are the function of the duration and intensity of use, preventive activity, directed especially towards adolescents, is of critical concern [13, 14]. The prevalence and usage of alcohol, cigarettes, and illicit substances vary by sex and geography $[4,6]$. Therefore, the current situation in individual regions regarding alcohol, cigarettes, and illicit substance use should be examined to establish the optimal strategy for prevention.

The aim of this study was to examine the use of alcohol, cigarettes, and illicit substances among adolescents in Poland and to extrapolate conditions and habits associated with this usage in younger age groups.

\section{Methods}

This study used a cross-sectional survey design in which adolescents completed the questionnaire on one occasion. All questions used in the questionnaire were authorderived.

The study was approved by the Bioethics Committee of the Medical University of Warsaw (No AKBE/187/2017).

In total, 541 adolescents aged 13-17 years old (mean $14 \pm 1$ years) enrolled in the study. The investigation was performed in gymnasia in towns of the county of Mazovia, Poland with varying number of inhabitants: below 20,000 (42.5\% ( $n=230)$ of enrolled participants), between 100,000$200,000(34.2 \%(n=185)$ of enrolled participants) and above $200,000(23.3 \%(n=126)$ of enrolled participants).

Each participant received a cover letter explaining the purpose of the study and ensuring confidentiality. The names of responders were not recorded on the questionnaire, thus rendering the data anonymous. Informed consent was indicated by voluntary participation in the survey. Completion of the questionnaire was done with previous instruction performed by the investigators. The collection rate was $100 \%$.

The questionnaire was divided into three parts. Each part included questions investigating alcohol, cigarette, and illicit substance use: the age of initiation, current use, frequency, the kind of illicit substances, access to these substances, places of consumption, and parent's knowledge and attitude towards the potential abuse.

Due to the fact that some answers were lacking, the number of questionnaires analysed was 538 in case of smoking and illicit substances use, and 535 in case of alcohol drinking.

\section{Statistical analysis}

The statistical analysis was performed using SPSS. Descriptive statistics of the collective data were generated using standard statistical parameters: percentage, mean, and standard deviation. Differences between females and males were analysed using either the Mann-Whitney U test or Pearson's chi-squared test. Differences between residents of towns with different numbers of inhabitants were analysed using either the Jonckheere-Terpstra test or Pearson's chi-squared test. The Kendall' tau-b correlation was used to analyse correlation of current use of alcohol, illicit substances and cigarette smoking. Results were considered statistically significant when $p<0.05$.

\section{Results}

\section{Alcohol drinking}

The total number of analysed questionnaires was 535 . According to this survey study, lifetime prevalence of alcohol included $54.4 \%(n=291)$ of participants, and currently $36.1 \%(n=193)$ drink alcohol, most of them less than once a month $(n=133,68.9 \%)$, but some $(n=$ $31,16.1 \%)$ drink daily. The average age of first alcohol consumption was $13-14$ years old $(n=98,18.3 \%)$, but for $10.3 \%$ of participants $(n=55)$ it was younger than eight years old. Among those who drink alcohol, 42.3\% $(n=82)$ indicated that it was supplied by someone older, $38.7 \%(n=75)$ bought alcohol themselves, and the rest from other sources. Parents of $49.5 \%(n=96)$ of the adolescents were aware of their alcohol consumption, 25.5\% $(n=49)$ accepted alcohol drinking at family celebrations, and $5.7 \%(n=11)$ accepted it completely.

The Jonckheere-Terpstra test and Pearson's chi-squared test revealed that in smaller towns more adolescents currently drink alcohol, the average age of their first alcohol consumption was lower, and more parents accepted alcohol drinking than in larger towns $\left(\chi^{2}(2, n=535)=47.60\right.$, $T_{J T}=53,580,50 ; z=3,61, \chi^{2}(4, n=193)=47.28$ respectively, $p<0.001$ in all cases).

The results referring to alcohol use (the age of initiation, current use of alcohol, frequency of use, and attitude of parents) stratified by sex are shown in Table 1 . The average age of first alcohol consumption was lower in males, more males currently drink alcohol, and frequency of drinking in males is higher when compared to females $(p<0.001, p<0.001, p=0.001$ respectively).

\section{Cigarette smoking}

The total number of analysed questionnaires was 538 . From the whole investigated group, 39.8\% $(n=214)$ of participants had lifetime prevalence of cigarette smoking, and currently $37.6 \%(n=201)$ smoke cigarettes, most of them daily $(n=111,55 \%)$. The average age of smoking initiation was $13-14$ years old $(n=106,19.7 \%)$, but for $4.8 \%$ of participants $(n=26)$ it was younger than eight years old. From those who smoke cigarettes, $23.9 \%(n=48)$ declared that they were supplied with cigarettes from someone older, $30.9 \%(n=62)$ bought cigarettes themselves, and $29.9 \%$ $(n=60)$ of participant get cigarettes at home because other residents smoke. The rest of the participants indicated other sources of supply. Parents of 35.8\% $(n=72)$ of the adolescents were aware of their cigarette smoking, 3.6\% 
Table 1 Alcohol drinking, the age of initiation, frequency of drinking and the parent's attitude to alcohol drinking among adolescents in Poland stratified by sex

\begin{tabular}{|c|c|c|c|c|c|c|c|c|c|}
\hline & & \multicolumn{6}{|l|}{ Sex } & & \multirow[t]{3}{*}{$p$} \\
\hline & & \multicolumn{2}{|c|}{ female } & \multicolumn{2}{|c|}{ male } & \multicolumn{2}{|l|}{ total } & & \\
\hline & & $n$ & $\%$ & $n$ & $\%$ & $N$ & $\%$ & & \\
\hline \multirow[t]{8}{*}{ The age of initiation } & Below the age of 8 years & 15 & 5,19 & 40 & 16,26 & 55 & 10,28 & \multirow[t]{8}{*}{$Z=4,71$} & \multirow[t]{8}{*}{$<0,001$} \\
\hline & $8-10$ years of age & 18 & 6,23 & 17 & 6,91 & 35 & 6,54 & & \\
\hline & $11-12$ years of age & 36 & 12,46 & 40 & 16,26 & 76 & 14,21 & & \\
\hline & 13-14 years of age & 52 & 17,99 & 46 & 18,70 & 98 & 18,32 & & \\
\hline & $15-16$ years of age & 12 & 4,15 & 13 & 5,28 & 25 & 4,67 & & \\
\hline & 17 years of age & 0 & 0,00 & 2 & 0,81 & 2 & 0,37 & & \\
\hline & Never drank alcohol & 156 & 53,98 & 88 & 35,77 & 244 & 45,61 & & \\
\hline & Total & 289 & 100,00 & 246 & 100,00 & 535 & 100,00 & & \\
\hline \multirow[t]{3}{*}{ Current alcohol drinking } & I don't drink alcohol & 206 & 71,28 & 136 & 55,28 & 342 & 63,93 & \multirow[t]{3}{*}{$x^{2}(1, N=535)=14,74$} & \multirow[t]{3}{*}{$<0,001$} \\
\hline & I drink alcohol & 83 & 28,72 & 110 & 44,72 & 193 & 36,07 & & \\
\hline & Total & 289 & 100,00 & 246 & 100,00 & 535 & 100,00 & & \\
\hline \multirow{7}{*}{$\begin{array}{l}\text { Frequency of alcohol drinking } \\
\text { [referred only to those, who } \\
\text { declared alcohol drinking] }\end{array}$} & daily & 8 & 9,64 & 23 & 20,91 & 31 & 16,06 & \multirow[t]{7}{*}{$Z=3,35$} & \multirow[t]{7}{*}{0,001} \\
\hline & 4 times a week & 1 & 1,20 & 8 & 7,27 & 9 & 4,66 & & \\
\hline & 2 times a week & 3 & 3,61 & 6 & 5,45 & 9 & 4,66 & & \\
\hline & Once a week & 1 & 1,20 & 5 & 4,55 & 6 & 3,11 & & \\
\hline & Once a month & 2 & 2,41 & 3 & 2,73 & 5 & 2,59 & & \\
\hline & Occasionally & 68 & 81,93 & 65 & 59,09 & 133 & 68,91 & & \\
\hline & Total & 83 & 100,00 & 110 & 100,00 & 193 & 100,00 & & \\
\hline \multirow{4}{*}{$\begin{array}{l}\text { parental attitude to alcohol } \\
\text { drinking [referred only to those, } \\
\text { who declared alcohol drinking] }\end{array}$} & Accept on family celebrations & 23 & 27,71 & 26 & 23,85 & 49 & 25,52 & \multirow[t]{4}{*}{$X^{2}(2, N=192)=0,54$} & \multirow[t]{4}{*}{0,797} \\
\hline & Accept & 4 & 4,82 & 7 & 6,42 & 11 & 5,73 & & \\
\hline & Don't accept & 56 & 67,47 & 76 & 69,72 & 132 & 68,75 & & \\
\hline & Total & 83 & 100,00 & 109 & 100,00 & 192 & 100,00 & & \\
\hline
\end{tabular}

Differences between female and male were analysed using either $U$ Mann-Whitney test or Pearson chi-square test. (Those, who currently do not drink alcohol could have the history of alcohol drinking in the past)

$(n=7)$ accepted cigarettes smoking occasionally, 6.7\% ( $n=$ 13) accepted it completely, and $10.3 \%(n=20)$ smoked with their children. It was very interesting that $28.9 \%(n=58)$ of participants smoked in school, almost the same number as on celebrations $(n=56,27.9 \%)$, and more than at home $(n=31,15.4 \%)$. The rest of investigated participants declared that they smoke in other places.

Pearson's chi-squared test revealed that in smaller towns more parents accept adolescent cigarette smoking than in larger towns $\left(\chi^{2}(6, n=195)=13.19, p<0.025\right)$.

The results referring to cigarette smoking (age of initiation, current use of cigarettes, frequency of use, and attitude of parents towards smoking) stratified by sex are shown in Table 2. The average age of initiation of smoking was lower in males, and more males than females currently smoke cigarettes ( $p<0.001$ in both cases).

\section{Illicit substance use}

The total number of analysed questionnaires was 538 . From the whole investigated group, $15.8 \%(n=85)$ of participants had a lifetime prevalence of illicit substance use, but currently only $10.8 \%(n=58)$ actively use those substances, $13.8 \%(n=8)$ of them more than three times a week. The average age of initiation of illicit substance use was $13-14$ years old ( $n=56,10.4 \%$ ), but for $1.3 \%$ of participants $(n=7)$ it was younger than eight years old. From those who use illicit substances, $32.8 \%(n=19)$ declared that they were supplied in the school neighborhood, $27.6 \% \quad(n=16)$ bought those substances from colleges, and 19\% $(n=11)$ were engaged in drug distribution themselves. The rest of the participants indicated other sources of supply. Parents of $22.4 \%(n=13)$ of adolescents engaging in illicit substance use were aware of it. It was very interesting that $50 \%(n=29)$ of participants use illicit substances at school, almost the same number as in entertainment clubs $(n=26,44.8 \%)$. The rest of investigated participants declared that they use these substances in other places.

Most of the investigated participants declared the use of marijuana $(n=34,58.6 \%)$, then LSD $(n=7,12.1 \%)$, 
Table 2 Cigarette smoking, the age of initiation, frequency of cigarettes smoking and the attitude of parents to cigarette smoking among adolescents in Poland stratified by sex

\begin{tabular}{|c|c|c|c|c|c|c|c|c|c|}
\hline & \multicolumn{6}{|l|}{ Sex } & & \multirow[t]{3}{*}{$p$} \\
\hline & & \multicolumn{2}{|c|}{ female } & \multicolumn{2}{|c|}{ male } & \multicolumn{2}{|l|}{ total } & & \\
\hline & & $n$ & $\%$ & $\bar{n}$ & $\%$ & $\bar{N}$ & $\%$ & & \\
\hline \multirow[t]{7}{*}{ The age of initiation } & Below the age of 8 years & 3 & 1,03 & 23 & 9,27 & 26 & 4,83 & \multirow[t]{7}{*}{$Z=4,09$} & \multirow[t]{7}{*}{$<0,001$} \\
\hline & $8-10$ years of age & 10 & 3,45 & 12 & 4,84 & 22 & 4,09 & & \\
\hline & $13-14$ years of age & 54 & 18,62 & 52 & 20,97 & 106 & 19,70 & & \\
\hline & $15-16$ years of age & 8 & 2,76 & 9 & 3,63 & 17 & 3,16 & & \\
\hline & $17-18$ years of age & 0 & 0,00 & 1 & 0,40 & 1 & 0,19 & & \\
\hline & Never smoked cigarettes & 195 & 67,24 & 129 & 52,02 & 324 & 60,22 & & \\
\hline & Total & 290 & 100,00 & 248 & 100,00 & 538 & 100,00 & & \\
\hline \multirow[t]{3}{*}{ Current cigarettes smoking } & I don't smoke cigarettes & 204 & 70,59 & 130 & 52,85 & 334 & 62,43 & \multirow[t]{3}{*}{$X^{2}(1, N=535)=17,84$} & \multirow[t]{3}{*}{$<0,001$} \\
\hline & I smoke cigarettes & 85 & 29,41 & 116 & 47,15 & 201 & 37,57 & & \\
\hline & Total & 289 & 100,00 & 246 & 100,00 & 535 & 100,00 & & \\
\hline \multirow{6}{*}{$\begin{array}{l}\text { Frequency of cigarettes smoking } \\
\text { [referred only to those, who declared } \\
\text { cigarettes smoking] }\end{array}$} & 15-20 cigarettes per day & 6 & 7,06 & 17 & 14,66 & 23 & 11,44 & \multirow[t]{6}{*}{$Z=0,73$} & \multirow[t]{6}{*}{0,467} \\
\hline & 10-15 cigarettes per day & 5 & 5,88 & 3 & 2,59 & 8 & 3,98 & & \\
\hline & 5-10 cigarettes per day & 23 & 27,06 & 29 & 25,00 & 52 & 25,87 & & \\
\hline & $1-5$ cigarettes per day & 11 & 12,94 & 17 & 14,66 & 28 & 13,93 & & \\
\hline & Occasionally & 40 & 47,06 & 50 & 43,10 & 90 & 44,78 & & \\
\hline & Total & 85 & 100,00 & 116 & 100,00 & 201 & 100,00 & & \\
\hline \multirow{5}{*}{$\begin{array}{l}\text { parental attitude to cigarettes } \\
\text { smoking [referred only to those, } \\
\text { who declared cigarettes smoking] }\end{array}$} & Accept occasionally & 2 & 2,47 & 5 & 4,39 & 7 & 3,59 & \multirow[t]{5}{*}{$X^{2}(3, N=195)=1,01$} & \multirow[t]{5}{*}{0,845} \\
\hline & accept & 5 & 6,17 & 8 & 7,02 & 13 & 6,67 & & \\
\hline & I smoke together with parents & 7 & 8,64 & 13 & 11,40 & 20 & 10,26 & & \\
\hline & Don't accept & 67 & 82,72 & 88 & 77,19 & 155 & 79,49 & & \\
\hline & Total & 81 & 100,00 & 114 & 100,00 & 195 & 100,00 & & \\
\hline
\end{tabular}

Differences between female and men were analysed using either U Mann-Whitney test or Pearson chi-square test. (Those, who currently do not smoke cigarettes could have the history of smoking in the past)

cocaine $(n=5,8.6 \%)$, amphetamines $(n=3,5.2 \%)$ and other $(n=9,15.5 \%)$.

Pearson's chi-squared test revealed that more adolescents use illicit substances in smaller towns than in larger towns $\left(\chi^{2}(2, n=550)=6.91, p<0.05\right)$.

The results referring to the use of illicit substances (age of initiation, current use, frequency of use) stratified by sex are shown in Table 3. The average age of first use of an illicit substance was lower in males, and more males than females currently use those substances $(p=$ 0.001 and $p<0.001$ respectively).

Correlations between those who currently drink alcohol, smoke cigarettes, and use illicit substances are shown in Table 4.

\section{Discussion}

Our results undoubtedly reflect that the use of alcohol and cigarettes is high among Polish adolescents, whereas the use of illicit substances is rather low. We did not investigate the reason but hypothesize that it could be cost. It has been proven that the price increase of cigarettes significantly reduced the rate of smoking in different age groups, including adolescents [15]. Another reason could be the support for banning illicit substances among adolescents in Europe, especially high for heroin, cocaine, and ecstasy [16]. Additonally detering might be that the use of illicit substances carries more negative consequences than the use of alcohol or cigarettes.

According to Scheithauer, et al. [17], the highest rates of alcohol use among European adolescents is in Eastern Europe. They also reported huge differences between countries, from $85.7 \%$ in Estonia to $21.6 \%$ in Iceland. The lifetime prevalence of alcohol consumption among adolescents in Norway reported by Mangerud et al. [4] was $54.4 \%$, and it was higher in females than in males, which is inconsistent with our results. The lifetime prevalence of alcohol use in Poland, as reported by Scheithauer, et al. [17], was $65 \%$. In our study, about $55 \%$ of participants reported lifetime alcohol use. This difference might result from the characteristics of investigated group. About 12\% of the group investigated by Scheithauer, et al. [17] were required to repeat a grade, which could influence the results. Another reason could be the different size of towns, where the investigation was conducted. It was also shown, 
Table 3 Illicit substances use, the age of initiation, and frequency of illicit substances use among adolescents in Poland stratified by sex

\begin{tabular}{|c|c|c|c|c|c|c|c|c|c|}
\hline & & \multicolumn{6}{|l|}{ Sex } & & \multirow[t]{3}{*}{$p$} \\
\hline & & \multicolumn{2}{|c|}{ female } & \multicolumn{2}{|c|}{ male } & \multicolumn{2}{|c|}{ total } & & \\
\hline & & $\bar{n}$ & $\%$ & $n$ & $\%$ & $\bar{N}$ & $\%$ & & \\
\hline \multirow[t]{6}{*}{ The age of initiation } & Below the age of 8 years & 1 & 0,34 & 6 & 2,42 & 7 & 1,30 & \multirow[t]{6}{*}{$Z=3,24$} & \multirow[t]{6}{*}{0,001} \\
\hline & $11-12$ years of age & 10 & 3,45 & 8 & 3,23 & 18 & 3,35 & & \\
\hline & 13-14 years of age & 19 & 6,55 & 37 & 14,92 & 56 & 10,41 & & \\
\hline & $15-16$ years of age & 2 & 0,69 & 2 & 0,81 & 4 & 0,74 & & \\
\hline & Never used illicit substances & 258 & 88,97 & 195 & 78,63 & 453 & 84,20 & & \\
\hline & Total & 290 & 100,00 & 248 & 100,00 & 538 & 100,00 & & \\
\hline \multirow[t]{3}{*}{ Current use of illicit substances } & I don't use illicit substances & 272 & 94,12 & 207 & 83,47 & 479 & 89,20 & \multirow[t]{3}{*}{$x^{2}(1, N=537)=15,71$} & \multirow[t]{3}{*}{$<0,001$} \\
\hline & I use illicit substances & 17 & 5,88 & 41 & 16,53 & 58 & 10,80 & & \\
\hline & Total & 289 & 100,00 & 248 & 100,00 & 537 & 100,00 & & \\
\hline \multirow{5}{*}{$\begin{array}{l}\text { Frequency of illicit substances use } \\
\text { [refers to those who declared illicit } \\
\text { substances use] }\end{array}$} & $1-2$ in life time & 2 & 11,76 & 7 & 17,07 & 9 & 15,52 & \multirow[t]{5}{*}{$Z=0,44$} & \multirow[t]{5}{*}{0,658} \\
\hline & Occasionally & 11 & 64,71 & 25 & 60,98 & 36 & 62,07 & & \\
\hline & 1-3 a week & 1 & 5,88 & 4 & 9,76 & 5 & 8,62 & & \\
\hline & More than 3 times a week & 3 & 17,65 & 5 & 12,20 & 8 & 13,79 & & \\
\hline & Total & 17 & 100,00 & 41 & 100,00 & 58 & 100,00 & & \\
\hline
\end{tabular}

Differences between female and men were analysed using either U Mann-Whitney test or Pearson chi-square test. (Those, who currently do not use illicit substances could have the history of the use in the past)

that adolescents' drinking was associated with adolescents' own socio-economic position [18]. The lifetime prevalence of alcohol use in Poland, as reported in The 2015 ESPAD (European School Survey Project on Alcohol and Other Drugs) Report was $83 \%$, what is more compared to our results. The difference could result from the characteristic of the sample. ESPAD survey was conducted among adolescents who turn 16 in the calendar year of the survey, and all samples were nationally representatives [19].

In 2010, the World Health Organization (WHO) reported that the prevalence of adolescent cigarette smoking in Poland was about $16 \%$ in males, and $12 \%$ in females. The prevalence of cigarette smoking among Polish adults the same year was 38 and $24 \%$ respectively for males and females [20]. According to our data, smoking among adolescents increased compared to the last report from the $\mathrm{WHO}$, and is now higher than the prevalence of smoking reported for adults in 2010. The lifetime prevalence of cigarettes smoking among adolescents in Poland, as reported in year 2015 by ESPAD was 55\%, what is more in compare to our results. The difference could result from the aforementioned difference in the characteristics of the sample [19].
Among the WHO regions, Europe has the highest prevalence of cigarette smoking among adults (28\%), and some of the highest among adolescents, but it differs across countries. According to the Health Behavior in School-aged Children (HBSC) study, cigarette use ranges from 5 to $51 \%$ in young males and from 1 to $53 \%$ in young females in Armenia and Greenland respectively. The lifetime prevalence of cigarette smoking among adolescents in Norway reported by Mangerud et al. [4] was $13.2 \%$, and it was higher in females than in males, which is inconsistent with our results. It was also reported that in some countries in Central-Eastern Europe cigarette smoking among adolescents is very similar to that among adults, which is in line with our results [20]. According to the 2010 WHO report, in the years 2000-2010, four tobacco advertising, promotion, and sponsorship restrictions were implemented. It seems that the results of those promotions were poor, and efforts towards reducing adolescent smoking must be retargeted.

According to Scheithauer, et al. [17], the lifetime prevalence of cannabis use in Poland is $15 \%$, and the average age of first use is 13-14 years old. According to ESPAD

Table 4 The Kendall' tau-b correlation between current use of alcohol, cigarettes and illicit substances

\begin{tabular}{|c|c|c|c|c|c|c|}
\hline & \multicolumn{2}{|c|}{ Current alcohol use } & \multicolumn{2}{|c|}{ Current cigarettes use } & \multicolumn{2}{|c|}{ Current illicit substances use } \\
\hline & $T_{b}$ & $p$ & $\tau_{b}$ & $p$ & $\tau_{b}$ & $p$ \\
\hline Current use of alcohol & & & 0,36 & $<0,001$ & 0,30 & $<0,001$ \\
\hline Current cigarettes use & 0,36 & $<0,001$ & & & 0,35 & $<0,001$ \\
\hline Current illicit substances use & 0,30 & $<0,001$ & 0,35 & $<0,001$ & & \\
\hline
\end{tabular}


[19] thelifetime prevalence of cannabis use among adolescents in Poland was $21 \%$. These results are slightly higher than those from our study, however these differences likely results from the aforementioned differences in investigated groups. Illicit substance use also differs across countries, for example, in Norway, the lifetime prevalence of illicit substance use among adolescents was $3.8 \%$, much less than in Poland [4].

The results discussed above differ from those on adolescents in the United States. It is estimated that about 25\% of American adolescents drink alcohol, 11\% smoke cigarettes, and as much as $20 \%$ use illicit substances [21].

It should be mention here, that according to ESPAD [19], the lifetime prevalence of the tranquilizers and sedatives use without prescription among adolescents in 2015 was most prevalent in Poland - 17\%, while the average use in all 35 ESPAD countries was $6 \%$. Also the use of anabolic steroids was high in Poland $-3 \%$, while the average use in ESPAD countries was 1\%.

Data discussed above clearly show that the use of addictive substances varies by region, country, and defined population. Our study additionally revealed that the use of these substances was higher in smaller towns than larger ones, and that there were sex-based differences; however, these data were partially contrary to data obtained in other countries $[4,17]$.

There are some aspects of the alcohol, cigarette, and illicit substance use that should be highlighted. First is the age of initiation. In our study the average age of first substance use was 13-14 years old, which for alcohol and illicit substances is in line with results published by Scheithauer, et al. [17]. They also reported that 15 and $2 \%$ of responders indicated that their first use of alcohol or cannabis respectively was at younger than ten years old, which is comparable with our results. Due to the fact that negative outcomes related to the use of these substances depend on the duration and intensity of use, the age of initiation should be paramount when considering preventive actions. Realistically, preventative measures should be directed not only to teenagers, but also to elementary school aged children.

Another important issue is the role of parents. The results of our study showed that half of the participants' parents knew about their alcohol use, and more than $30 \%$ accepted it completely or at least at family celebrations. In case of cigarettes the situation was similar, however, fewer parents were aware of it though as much as $10 \%$ smoked cigarettes together with their children. The number of parents aware of illicit substance use was even lower than for alcohol and cigarettes. These results reveal that parental awareness of alcohol or cigarette use among children in Poland is lower than other countries in Europe [22]. The parental role is very important, but also very difficult and ambiguous. It was shown that the provision of alcohol by parents is associated with lower levels of harm at the same drinking and bingeing frequency $[6,22]$. Children who consumed alcohol without parental knowledge were less likely to report having a parental discussion about alcohol in the last three months or report lifetime receipt of at least one parental protective measure [22]. It is important to acknowledge that the acceptance rate of alcohol and cigarette use is high in Poland, which likely results from many factors, including the lack of sufficient knowledge about associated problems and outcomes. Our results clearly show that preventive actions should also be directed to the parents, and should include information on the harmful outcomes of substance use and the symptoms of this use in children.

Another issue is the role of school in protecting adolescents from substance use in Poland. Our study revealed that between 29 and $50 \%$ of participants smoke or use illicit substances at school. A lot of users buy illicit substances in the school's neighborhood. In general, schools represent an opportune setting for interventions to prevent adolescent substance use because they have access to large number of adolescents and have curricula and other opportunities that promote health and well-being. Our results suggest that the educational and protective role of schools should be strengthened.

Adolescents in Poland have easy access alcohol and cigarettes, despite laws prohibiting the sale of alcohol and cigarettes to people under 18 years old. Trafficking and use of illicit substances is also prohibited by law, regardless of age. The common method of accessing alcohol and cigarettes was through older individuals, which has been previously reported [23]. Surprisingly, notable numbers of underage people report purchasing their own alcohol and cigarettes, at about 39 and $62 \%$ respectively. For alcohol, this is higher than in Great Britain, where only $28 \%$ of underage drinkers have purchased alcohol themselves [23]. These results showed failure to comply with minimum age legislation in Poland.

Our study confirmed that cigarette and alcohol use share common etiological factors and often develop concurrently [24]. Animal studies have revealed reinforcing interactions between these two substances, which are age and sex dependent with adolescent males being the most sensitive to it. In humans, it is well established in the literature that cigarette use likely increases the vulnerability of teenage boys to alcohol use $[5,25]$.

Some limitations of the study need to be taken into account. The investigated group did not include adolescents who were not a part of the regular school system. Very important limitation of the present study is relying on self-reported data. Therefore this report might be influenced by information bias, which would have led to an under- or overestimation of cigarette smoking, alcohol drinking and illicit substances use. This was also 
cross-sectional study, and the temporal nature of associations cannot be excluded.

\section{Conclusion}

According to this survey study, the rate of alcohol, cigarette, and illicit substance use in Poland is high and differs between small and large towns. Parental awareness of alcohol or cigarette use among children in Poland is low, and schools hardly fulfil their educational and protective role. These circumstances should always be considered when planning preventative action. The conclusion from an article by Dwyer-Lindgren, et al. [26] is that public health is local, and information on local challenges is required to increase resident's and policy maker's awareness. The article refers to life expectancy and the mortality rate, and their conclusions have universal significance. Alcohol, cigarette, and illicit substance use are responsible for $9 \%$ of the global disease burden and $12 \%$ of deaths worldwide $[4,27]$. Lowering the rates of alcohol, cigarettes and illicit substances use should lower these numbers. Preventative actions must consider to a greater extent the local conditions and challenges, and they should gravitate from universal methods towards more personalized approaches. Our findings provide local information for revising global prevention programs.

\section{Abbreviations}

ESPAD: European School Survey Project on Alcohol and Other Drugs; HBSC: Health Behavior in School-aged Children; WHO: World Health Organization

\section{Acknowledgements}

Not applicable

\section{Funding}

No funding was received for this study.

\section{Availability of data and materials}

The data used in this study can be obtained upon request to the corresponding author.

\section{Authors' contributions}

MN, AM, MP planned the study, arranged the data, performed the statistical analysis, BC-P performed the statistical analysis, and wrote the first draft and the final version of the manuscript, commented on the manuscript and contributed to all sections. All authors read and approved the final manuscript.

\section{Ethics approval and consent to participate}

The study was approved by the Bioethics Committee of the Medical University of Warsaw (No AKBE/187/2017).

\section{Consent for publication}

Not applicable.

\section{Competing interests}

The authors declare that they have no competing interests.

\section{Publisher's Note}

Springer Nature remains neutral with regard to jurisdictional claims in published maps and institutional affiliations.
Received: 20 June 2018 Accepted: 9 November 2018

Published online: 29 November 2018

\section{References}

1. Moss HB, Chen CM, Yi HY. Early adolescent patterns of alcohol, cigarettes, and marijuana polysubstance use and young adult substance use outcomes in a nationally representative sample. Drug Alcohol Depend. 2014;136:151-62. https://doi.org/10.1016/j.drugalcdep.2013.12.011.

2. Alikasifoglu M, Erginoz E, Ercan O, Uysal O, Albayrak-Kaymak D, Ilter O. Alcohol drinking behaviors among Turkish high school students. Turk J Pediatr. 2004:46:44-53.

3. Myers MG, Kelly JF. Cigarette smoking among adolescents with alcohol and other drugs use problems. Alcohol Res Health. 2006;29:221-7.

4. Mangerud WL, Bjerkeset O, Holmen TL, Lydersen S, Indredavik MS. Smoking, alcohol consumption, and drug use among adolescents with psychiatric disorders compared with a population based study. J Adolescence. 2013;37: 1189-99. https://doi.org/10.1016/j.adolescence.2014.08.007.

5. Larraga A, Belluzi JD, Leslie FM. Nicotine increases alcohol intake in adolescence male rats. Front Behave Neurosci. 2017;11:25. https://doi. org/10.3389/fnbeh.2017.00025.

6. Bellis MA, Phillips-Howard PA, Hughes K, Hughes S, Cook PA, Morleo M, Hannon K, Smallthwaite L, Jones L. Teenage drinking availability and pricing: a cross-sectional study of risk and protective factors for alcohol-related harms in school children. BMC Public Health. 2009;9:380. https://doi.org/10. 1186/1471-2558-9-380

7. Bello B, Moultrie H, Somji A, Chersich MF, Delany-Moretwe S. Alcohol use and sexual risk behavior among men and women in inner-city Johannesburg, South Africa. BMC Public Health. 2017;17(Suppl 3):548. https://doi.org/10.1186/s12889-017-4350-4.

8. Strong C, Juon HS, Ensminger ME. Long-term effects of adolescent smoking on depression and socioeconomic status in adulthood in an urban African American cohort. J Urban Health. 2014;91:526-40. https://doi.org/10.1007/ s11524-013-9849-0.

9. Piirtola M, Kaprio J, Silventoinen K, Svedberg P, Korhonen T, Ropponen A. Association between long-term smoking and leisure-time physical inactivity: a cohort study among Finnish twins with a 35-year follow-up. Int J Public Health. 2017:62:819-29. https://doi.org/10.1007/s00038-017-0975-4.

10. Orlando M, Tucker JS, Ellickson PL, Klein DJ. Concurrent use of alcohol and cigarettes from adolescents to young adulthood: an examination of developmental trajectories and outcomes. Subst Use Misuse. 2005;40:1051-69.

11. Charrier L, Berchialla P, Galeone D, Spizzichino L, Borraccino A, Lemma P, Dalmasso P, Cavallo F. Smoking habits among Italian adolescents: what has changed in the last decade? Biomed Res Int. 2014;2014:287139. https://doi. org/10.1155/2014/287139.

12. Ostergren $\mathrm{O}$, Martikainen $\mathrm{P}$, Lundberg $\mathrm{O}$. The contribution of alcohol consumption and smoking to educational inequalities in life expectancy among Swedish men and women during 1991-2008. Int J Public Health. 2017:63:41-8. https://doi.org/10.1007/s00038-017-1029-7.

13. Ellicson PL, Tucker JS, Klein DJ. Ten-years prospective study of public health problems associated with early drinking. Pediatrics. 2003;111:949-55.

14. Stueve A, O'Donnel LN. Early alcohol initiation ans subsequent sexual and alcohol risk behaviors among urban youths. Am J Public Health. 2005;95: 887-93.

15. Ho LM, Schafferer C, Lee JM, Yeh CY, Hsieh CJ. The effect of cigarette price increases on cigarette consumption, tax revenue, and smoking-related death in Africa from 1999 to 2013. Int J Public Health. 2017;62:899-909. https://doi.org/10.1007/s00038-017-0980-7.

16. Palladino R, Hone T, Filippidis FT. Changes in support for bans of illicit drugs, tobacco, and alcohol among adolescents and young adults in Europe, 2008-2014. Int J Public Health. 2017;63:23-31. https://doi.org/10. 1007/s00038-017-1025-y.

17. Scheithauer H, Gobel K, Soellner R, Huber S. Descriptive analysis of substance use in Europe. In: Steketee $\mathrm{M}$, Jonkman $\mathrm{H}$, Berten $\mathrm{H}$, Vettenburg $\mathrm{N}$, editors. Alcohol use among adolescence in Europe. Utrecht: Environmental research and preventive action. Vervey Jonker Instituut; 2013.

18. Bosque-Prous M, Kuipers MAG, Espelt A, Richter M, Rimpela A, Perelman J, Federico B, Brugal MT, Lorant V, Kunst AE. Adolescent alcohol use and parental and adolescent socioeconomic position in six European cities. BMC Public Health. 2017;17:646. https://doi.org/10.1186/s12889-017-4635-7.

19. European School Survey Project on Alcohol and Other Drugs web site available at http://www.espad.org. Accessed 08 Sept 2018. 
20. World Health Organization, Regional Office for Europe web site available at http://www.euro.who.int/en/health-topics/disease-prevention/tobacco/dataand-statistics. Accessed 26 Oct 2017.

21. Lipari RN, Crane EH, Strashny A, Dean D Jr. A Day in the life of American adolescents: substance use facts update. The CBHSQ report. Rockville (MD): Substance Abuse and Mental Health Services Administration (US); 2013.

22. Morleo M, Cook PA, Elliot G, Phillips-Howard PA. Parental knowledge of alcohol consumption: a cross sectional survey of 11-17 year old schoolchildren and their parents. BMC Public Health. 2013;13:412. https//doi.org/10.1186/1471-2458-13-412.

23. Morleo M, Cook PA, Bellis MA, Smallthwaite L. Use of fake identification to purchase alcohol amongst 15-16 years olds: a cross sectional survey examining alcohol access, consumption and harm. Subst Abuse Treat Prev Policy. 2010;5:12. https://doi.org/10.1186/1747-597X-5-12.

24. Ljubotina D, Galic J, Jukic V. Prevalence and risk factors of substances use among urban adolescents: questionnaire study. Croat Med J. 2004:45:88-98.

25. Abreu-Villaca Y, Manhaes AC, Krahe TE, Filgueiras CC, Ribeiro-Carvalho A. Tobacco and alcohol use during adolescence: interactive mechanisms in animal models. Biochem Pharmacol. 2017;144:1-17. https://doi.org/10.1016/ j.bcp.2017.06.113.

26. Dwyer-Lindgren L, Stubbs RW, Bertozzi-Villa A, Morozoff C, Callender C, Finegold SB, Shirude S, Flaxman AD, Laurent A, Kern E, Duchin JS, Fleming $D$, Mokdad AH, Murray CJL. Variation in life expectancy and mortality by cause among neighbourhoods in King County, WA, USA, 1990-2014: a census tract-level analysis for the global burden of disease study 2015 . Lancet Public Health. 2017;2:e400-10. https://doi.org/10.1016/524682667(17)30165-2

27. Hodder RK, Freund M, Bowman J, Wolfenden L, Campbell E, Dray J, Lecathelinais C, Oldmeadow C, Attia J, Wiggers J. Effectiveness of pragmatic school-based universal resilience intervention in reducing tobacco, alcohol and illicit substances use in population of adolescence: cluster-randomized controlled study. BMJ Open. 2017;7(8):e016060. https://doi.org/10.1136/ bmjopen-2017-016060

Ready to submit your research? Choose BMC and benefit from:

- fast, convenient online submission

- thorough peer review by experienced researchers in your field

- rapid publication on acceptance

- support for research data, including large and complex data types

- gold Open Access which fosters wider collaboration and increased citations

- maximum visibility for your research: over $100 \mathrm{M}$ website views per year

At $\mathrm{BMC}$, research is always in progress.

Learn more biomedcentral.com/submissions 